\title{
UM CAMPO EMERGENTE: A ARQUEOLOGIA DA MÚSICA E SUAS INTERFACES COM O PATRIMÔNIO
}

Fábio Vergara Cerqueira ${ }^{1}$

\section{RESUMO}

A presente entrevista com o arqueólogo Fábio Vergara Cerqueira traz informações sobre um campo emergente nos estudos arqueológicos, a assim chamada Arqueologia da Música, que conta, entre suas ramificações, com a especialidade da Arqueoorganologia, que, na sua variante iconográfica, é uma área de atuação deste arqueólogo. Esta nova disciplina se desenvolve em um domínio epistemológico bastante complexo e interdisciplinar e, mais recentemente, como se observa na articulação de programas internacionais de pesquisa, apresenta intensa integração à temática patrimonial, ligada, sobretudo, ao patrimônio dito imaterial, com forte valorização de saberes musicais de comunidades tradicionais.

Palavras-chave: Arqueologia da música; Arqueoorganologia; Iconografia da música; Grécia antiga; Patrimônio musical.

\section{ABSTRACT}

The interview with the archaeologist Fábio Vergara Cerqueira (Universidade Federal de Pelotas) brings information about an emerging field in archaeological studies, the so called Music Archaeology. It includes, among its ramifications, the expertise of archaeoorganology (archaeology of musical instruments), that, in its iconographical variation, consists of an expertise area of this archaeologist. This new discipline develops in a very complex and interdisciplinary epistemological domain; and, more recently, as we observe in the articulation of international research projects, it presents an intensive integration with cultural heritage debates, linked mainly to the so called immaterial heritage, valuing strongly the musical knowledge of traditional communities.

Key-words: Music archaeology; Archeoorganology; Music Iconography; ancient Greece; musical heritage.

\section{RESUMÉE}

L'interview avec l'archéologue Fábio Vergara Cerqueira apporte des informations sur un domaine émergent dans les études archéologiques, ce que l'on appelle l'Archéologie de la Musique. Elle compte parmi ses branches, avec la spécialité de Archéoorganologie, laquelle, dans sa variante iconographique, constitue un domaine d'expertise de cet archéologue. Cette nouvelle discipline se développe dans un domaine épistémologique plutôt complexe et interdisciplinaire. Et, plus récemment, comme on le voit dans les programmes internationaux de recherche conjoints, la Archeologie de la Musique dispose

\footnotetext{
${ }^{1}$ Rua General Telles, n. 861, apto.1105, Pelotas, RS 053 84831790; fabiovergara@uol.com.br
} 


\section{Revista de Arqueologia Pública}

d'une forte intégration avec le thème du patrimoine culturel, en particulier celui lié au dit patrimoine immatériel, avec une forte appréciation des connaissances musicales des communautés traditionnelles.

Mots cléfs: Archéologie de la Musique; Archéoorganologie; Iconography de la Musique; Grèce ancienne; patrimoine musicale.

\section{Sobre o entrevistado}

Fábio Vergara Cerqueira é doutor em Antropologia Social, concentração em Arqueologia Clássica; Pesquisador CNPq PQ-2 em Arqueologia Histórica; Bolsista Fundação Humboldt "Pesquisador Experiente" em Arqueologia Clássica; Pesquisador Visitante na Universidade de Heidelberg, Centro de Ciências da Antiguidade, Instituto de Arqueologia Clássica, Alemanha; Professor Permanente do Programa de Pós-Graduação em Memória Social e Patrimônio Cultural; Professor Permanente do Programa de PósGraduação em História Departamento de História, Instituto de Ciências Humanas, Universidade Federal de Pelotas; Coordenador do Laboratório de Estudos sobre a Música Grega - LECA/UFPel; Membro do Laboratório de Antropologia e Arqueologia LEPAARQ/UFPel; Editor dos Cadernos do LEPAARQ. Textos em Antropologia, Arqueologia e Patrimônio; Coordenador do Museu Etnográfico da Colônia Maciel; Coordenador do Museu da Colônia Francesa.

Além de se ser membro da MOISA International Society for the Study of Ancient Greek and Roman Music and its Heritage; Arion Society; Sociedade Brasileira de Estudos Clássicos - SBEC; Associação nacional de História - ANPUH; Sociedade Brasileira de Arqueologia - SAB.

\section{Sobre música e história, um prólogo}

\section{O interesse do conhecimento histórico pela música é algo novo?}

Desde a Antiguidade grega, a música foi um tema que despertou interesse de historiadores e estudiosos do passado. Alegres anedotas ou lendas dramáticas sobre eventos musicais, de fundo mítico ou humano, permeavam o pensamento de vários autores em suas remissões ao passado, não somente historiadores, mas até mesmo poetas e filósofos. E por meio destas histórias, ou estórias, falavam bem mais do que simplesmente (se é que isto é pouco) de uma história da música ou do músico em si. Quando contavam do duelo musical entre Apolo e o sileno Mársias, que resultou no esfolamento e morte do último, estava em 


\section{Revista de Arqueologia Pública}

jogo o embate entre o apolinismo e o dionisismo na cultura antiga, representações antagônicas entre cultura e natureza, civilização e barbárie. Quanto contavam de músicos que haviam sido proibidos de se apresentarem em alguma cidade, como Esparta, por que acrescentavam uma corda ao seu instrumento, mais do que tudo estava em jogo a relação entre música e política, e os próprios sistemas políticos. Quando Plutarco, na biografia de Alcibíades, nos conta da rebeldia deste jovem, que se nega a acompanhar as aulas do professor de aulós (instrumento de sopro formado por dois tubos soprados por meio de palheta de junco, e compostos de diversas seções), dizendo que este instrumento é próprio aos tebanos, enquanto os atenienses deveriam ter a lýra por seu instrumento, seu discurso traz à tona valores de afirmação da identidade ateniense e, ao mesmo tempo, o cenário de rivalidade com a vizinha Tebas. Contam também do rico citaredo Arion que, ao voltar de uma tournée pelo sul da Itália, onde havia ganho muito dinheiro, é ameaçado de morte pelos marinheiros da embarcação que o levava, os quais, querendo roubar-lhe sua fortuna, dão-Ihe a chance de um último pedido: o músico pede que lhe deixem cantar acompanhado de sua cítara sobre a proa do navio. Ao fazê-lo, aparece um golfinho, sobre o qual se joga, fugindo à sua morte. Esta narrativa nos reporta ao bestiário grego, e à relação muito particular que alguns animais, como golfinhos, cisnes e cigarras, mantinham, em seu imaginário, com a música. Até golfinhos tocando flauta foram capazes de representar em pintura de vaso! A história, ao mesmo tempo, tem um valor sociológico, pois revela o fato de que músicos podiam alcançar a celebridade, formar riqueza e rodar o mundo, gerando admiração e inveja. Muita erudição sobre o passado teve a música como tema. Poderia citar aqui o Banquete dos Sábios (Deipnosophistai), de Ateneu e o Sobre a Música (Peri Mousikes), de Plutarco, obra que recebeu recentemente sua primeira - e excelente tradução para o português, feita por Roosevelt Rocha (Universidade Federal do Paraná) e publicada pela Universidade de Coimbra (ROCHA, 2010) ${ }^{2}$. Plutarco nos fala da origem dos instrumentos e dos gêneros musicais, nos conta sobre músicos e suas obras, nos fala sobre os valores morais (a teoria do ethos musical) das diferentes formas de expressão musical. Discorre ainda sobre vários aspectos da teoria musical e apresenta, inclusive, certa consistência historiográfica com relação ao uso de fontes variadas disponíveis ao seu tempo, de modo que constatamos que, no séc. II da Era Comum, ainda eram conhecidos muitos autores antigos que haviam escrito sobre história da música havia cerca de um

2 Arquivo em pdf da obra disponibilizado pela Imprenta da Universidade de Coimbra: https://bdigital.sib.uc.pt/ispui/bitstream/123456789/43/1/obras morais sobre o afecto aos filhos so bre a musica.pdf 


\section{Revista de Arqueologia Pública}

milênio. Isto revela que, entre os gregos, havia, podemos dizer, uma especialidade, entre os conhecimentos históricos: uma tradição de história da música.

E nas últimas décadas, como tem sido o interesse pelo passado musical por parte de historiadores e arqueólogos?

Faço este prólogo para mostrar-lhes como a relação entre a pesquisa histórica e a música não é algo novo na tradição ocidental. Contudo, ao longo do último século, e sobretudo nas três últimas décadas, o estudo ganhou um novo fôlego, impulsionado pelas possibilidades do conhecimento inter e multidisciplinar. E, seja no presente, seja no passado distante, estudar o passado da cultura musical é muito mais do que simplesmente estudar as práticas musicais e seus agentes. Tudo bem que de fato houve - e há - entre historiadores da música uma corrente fortemente influenciada por uma perspectiva positivista, que busca uma visão idealizada da história da música, algo descolada de seus contextos históricos, uma história naquele espírito da história dos heróis, em busca do gênio dos grandes mestres da música. Mas não é disto que falo aqui: falo da música como uma perspectiva para se pensar o passado da humanidade. Não é só pensar a música, mas pensar as sociedades pretéritas através da música, e entender a música através destas sociedades. Apropriando-me do conceito de Marcel Mauss, diria que a maior vantagem está em estudar a música como um "fato social total", no qual as mais variadas facetas da vida social e cultural estão imbricadas umas nas outras, costurando uma rede de sentidos que permeiam e constituem a cotidianidade humana.

Assim, nas biografias de Plutarco, ao apontar a importância da educação musical na formação dos homens públicos gregos, e ao mostrar a ausência desta na juventude dos biografados romanos, nosso biógrafo evoca um traço presente na memória social grega como um aspecto distintivo, como um traço de identidade cultural dos gregos, em oposição aos romanos. Vê-se então como na estrutura narrativa recorrente no conjunto das biografias de Plutarco há uma articulação entre música e memória cultural dos gregos, em pleno Império romano do segundo século.

\section{Horizontes contemporâneos de estudo do passado musical}

\section{Que lugar tem tido a música na historiografia brasileira atual?}

Nas últimas décadas, o interesse por parte de historiadores brasileiros pela música como objeto de pesquisa tem aumentado muito. Entre tantos, devemos lembrar de Marco 


\section{Revista de Arqueologia Pública}

Napolitano (USP), autor da obra de referência sobre o assunto, História e Música (2002), publicada pela Autêntica, de Belo Horizonte, cujo subtítulo revela o enquadramento historiográfico no âmbito da Nova História Cultural: "História cultural da música popular".

Pelo viés da história da música popular, muitas pesquisas têm apresentado o Brasil do século XX desbaratado pela experiência da música popular. Recomendo ao leitor interessado que busque, por exemplo, o trabalho de Márcia Ramos de Oliveira (Universidade do Estado de Santa Catarina), sobre Lupicínio Rodrigues (OLIVEIRA, 2002). Contudo, é muito mais enriquecedor olharmos para os comportamentos e sons do passado musical a partir de uma perspectiva epistemológica mais ampla, que desfruta de diálogos interdisciplinares. Não podemos, então, falar da interface entre História \& Música, ignorando as interfaces entre Etnologia \& Música e entre Arqueologia \& Música, visto que, no campo dos comportamentos musicais humanos, buscam compreender estas experiências enfocando objetos ou fontes variadas, mas é sempre ao homem e sua música que se referem.

E como se insere Arqueologia da Música neste cenário de busca do conhecimento da música das sociedades pretéritas?

Neste sentido, acho muito didático o fluxograma proposto por Arnd Adje Both (2009: 04), que apresenta o esquema epistemológico que estrutura o vasto campo de estudos da Arqueologia da Música (Fig. 01).

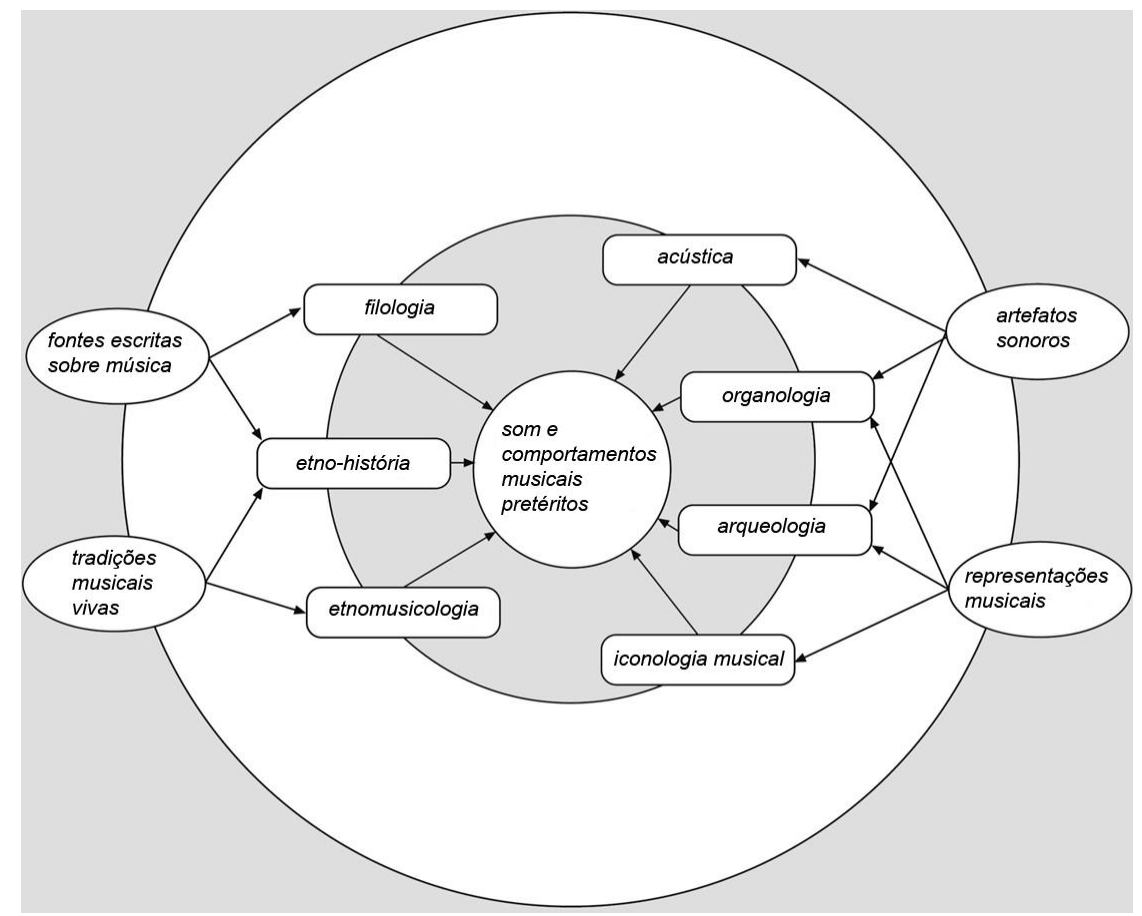




\section{Revista de Arqueologia Pública}

Figura 01 - Fluxograma do campo epistemológico da Arqueologia da Música, conforme Arnd Adje Both (2009:4). Adaptado por Cláudio Peixoto Pickersgil (Bolsista PIBITI/CNPq).

Adje Both mostra-nos como um conjunto de disciplinas concorrem para estruturar o campo da Music Archaeology, acarretando consequências teóricas e metodológicas sobre este campo de pesquisa. Em busca da compreensão dos comportamentos e sons do passado musical, dois campos multidisciplinares se somam.

No primeiro campo, temos o uso das fontes escritas e das tradições musicais vivas. Estas fontes escritas compõem os estudos filológicos e históricos: tratados musicais, referências literárias a comportamentos, relatos sobre músicos e obras, entre tantos outros tipos de registros. As tradições musicais vivas são observadas pelo antropólogo, interessado pela Antropologia da Música, que produz uma interpretação etnomusicológica destas experiências musicais. Já os estudos etno-históricos, se baseiam em relatos feitos no passado sobre costumes de povos iletrados, ou cuja escrita se manteve por muito tempo desconhecida. Exemplo de fontes etno-históricas são os missionários no tempo da colonização da América e os viajantes, que nos reportam situações cotidianas e rituais em que a música se destaca.

No segundo campo, arranjam-se outras disciplinas e tipos de fontes. Basicamente, são dois tipos de registros empíricos: os artefatos que produzem sons, nomeadamente os instrumentos musicais, mas não só, e as representações visuais de cenas musicais. Por excelência, o estudo dos instrumentos musicais, preservados pelas tradições ou encontrados no contexto arqueológico, são objetos de uma disciplina em particular: a organologia, que se dedica ao estudo dos instrumentos musicais. Daí um ramo particular da arqueologia, a arqueoorganologia. Porém, estudos modernos têm possibilitado uma profícua interação com a física, no estudo da acústica. Já as representações visuais, alimentam três disciplinas: a própria organologia, a arqueologia e a iconologia musical.

\section{E como têm avançado os estudos de Arqueologia da Música e de Iconologia Musical?}

Em escala mundial, grupos de pesquisa, publicações, eventos e projetos internacionais têm se dedicado a alguns destes campos, que avançam sempre pelo caminho da multidisciplinaridade.

O interesse pela iconologia musical motivou a criação, em 1971, do RldIM - Répertoire Internationale d'Iconographie Musicale $^{3}$, destinado à indexação e catalogação das fontes visuais sobre a música. O projeto surge sob a chancela do ICOM - International Council of 


\section{Revista de Arqueologia Pública}

Museums, revelando o quanto as imagens sobre música se tornaram importantes para a preservação do Patrimônio Cultural da Humanidade. Os estudos dos repertórios de iconografia musical foram publicados pelo "RIdIM Newsletter", de 1975 a 1997. A partir de 1998, foi substituída pela "Music and Art. International Journal for Music Iconography". Em 2012 e 2013, ocorreram em Salvador as conferências internacionais do RIdIM Brazil, mostrando a vitalidade que os estudos de iconografia da música assumiram entre nós. Exemplo disto pode ser conferido na coletânea "Estudos luso-brasileiros em iconografia musical" (ver SOTUYO, 2015). No início, o foco dos estudiosos brasileiros voltou-se muito para os repertórios visuais católicos, com representações musicais; atualmente, sem abandonar o interesse inicial, fortemente alimentado pela patrimonialização consolidada destes bens, os interesses se ampliaram bastante, incluindo do estudo de fotografias em preto e branco conservadas nos conservatórios de música às capas de discos de vinil dos anos 1970 e 1980. Sobre as fotografias, trago como exemplo nosso estudo "Iconografia musical e performance através de fotografias" (NOGUEIRA, VERGARA CERQUEIRA e MICHELON, 2015: 33-64).

Como exemplo do dinamismo e inovação nesta área, citemos a realização, em 2014, do 9o Simpósio do Grupo Internacional de Estudo sobre Arqueologia da Música, vinculado à Seção Oriental do Instituto Alemão de Arqueologia, sob a coordenação do arqueólogo Ricardo Eichmann. Arqueologia pré-histórica, clássica, oriental, medieval e mesmo moderna contribuem para as discussões sobre a Arqueologia da música. Grandes avanços foram dados graça à grande cooperação internacional nesta área, inclusive em termos de reconstituição de instrumentos e sons das músicas pretéritas. Intenso debate se trava sobre a antiguidade das primeiras flautas em osso conhecidas - as datações recuam há aproximadamente 35 mil anos. (Fig. 02) Harpas egípcias e órgão hidráulico grego somamse a instrumentos das mais variadas regiões, pesquisados e tocados por arqueólogos, etnomusicólogos e músicos. 


\section{Revista de Arqueologia Pública}
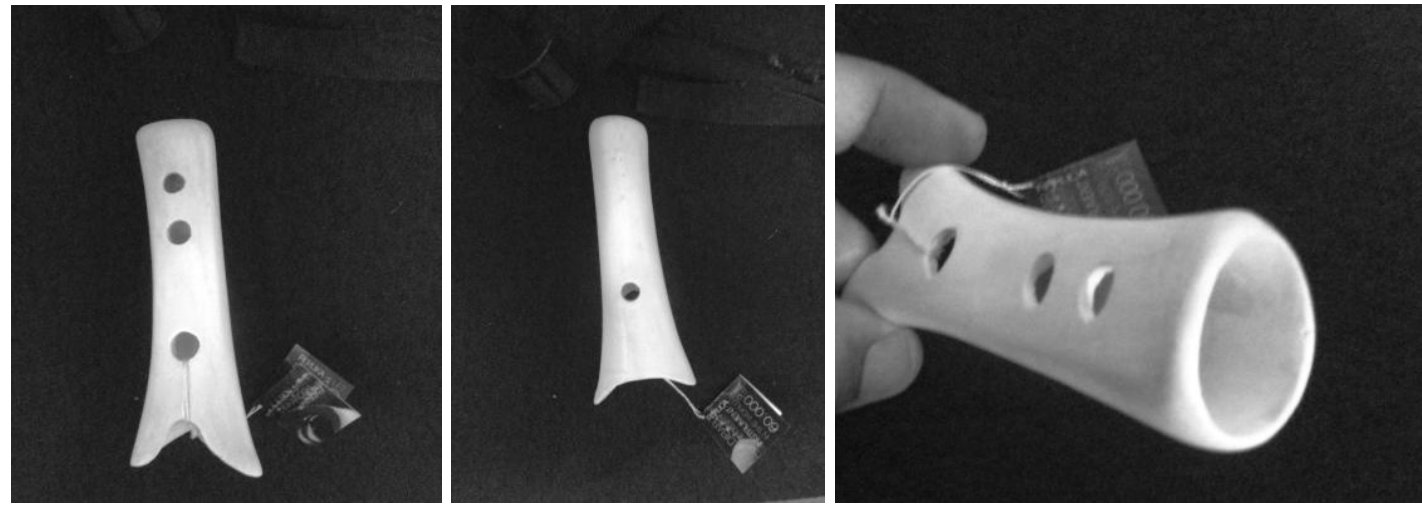

Figura 02 - "Flauta" paleolítica. Visão superior, inferior e lateral de protótipo fac símile de um dos mais antigos instrumentos musicais, datada de aprox. 35 mil anos A.P., encontrada na Polônia. Apresentada na "Kleine Sommerschule - Musikarchäologie" - Uma introdução ao estudo da música antiga, 07-08 Setembro, 2014. Foto: F. Vergara Cerqueira (Berlim, 2014)

Assim a Arqueologia da Música acaba se irmanando a disciplinas propriamente musicais. Um exemplo seria a reconstrução de instrumentos musicais da Antiguidade, formando-se aí uma nova especialidade na luthieria. Outro seria a própria performance musical, que imprescinde da primeira, mas inclui uma série de outros saberes, que envolve conhecimentos da teoria musical antiga e interpretação da técnica para empunhar e tocar o instrumento, com base, por exemplo, na iconografia. Neste sentido, deveríamos destacar o trabalho do musicólogo austríaco Stephan Hagen, nome de referência na atualidade na confecção de instrumentos musicais antigos e respectiva performance. Tive a oportunidade de acompanhar de perto seu trabalho de reconstrução e execução musical da kithara ou mesmo de protótipos variados de auloi, até mesmo usando materiais modernos como o PVC ou acrílico (Fig. 03). Fazer (re)viver a música da Antiguidade é uma experiência que está no horizonte da Arqueologia da Música. 


\section{Revista de Arqueologia Pública}

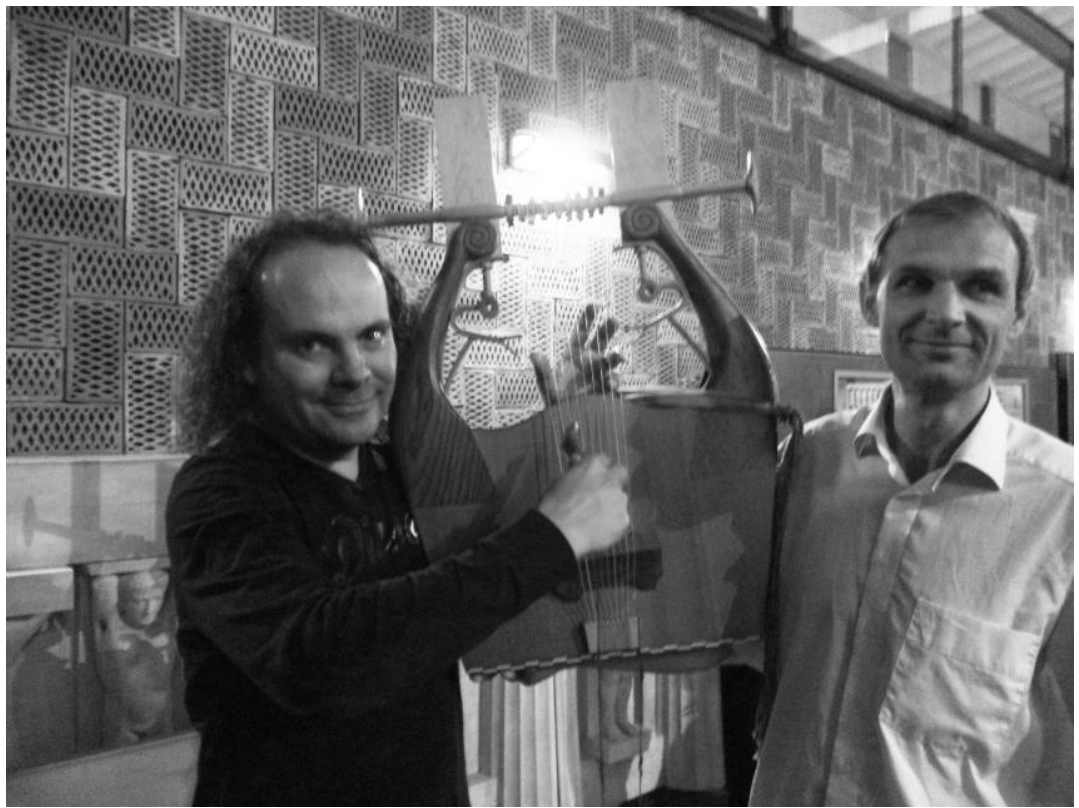

Figura 03 - O musicólogo Stephan Hagen, criador deste modelo moderno da kithára grega, e o arqueólogo Fábio Vergara Cerqueira, empunhando o instrumento conforme a posição utilizada pelos antigos citaredos. Foto: Arquivo pessoal F.V.C. (Agrigento, Itália, 2013)

Entre os grupos internacionais de pesquisa, destaquemos o ISGMA - International Study Group on Music Archaeology, baseado no Instituto Alemão de Arqueologia, e o ICTM Study Group on Music Archaeology. O ITCM, visando a fomentar a pesquisa em arqueologia da música nas Américas, deu início à nova série "Music \& Ritual: Bridging Material \& Living Cultures", cujo primeiro volume foi lançado em 2013. Para os interessados, destaquemos o encontro realizado em agosto de 2015 em Biskunpin, na Polônia - o "14th Symposium of the ICTM Study Group on Music Archaeology", ou ainda o ISGMA, que anuncia seu próximo simpósio para a China ${ }^{4}$.

\section{Entre patrimônio cultural imaterial e memória social}

Que relações podem ser identificadas entre a emergência da Arqueologia da Música, o patrimônio cultural e as comunidades?

Após algumas décadas de desatenção, hoje o patrimônio cultural musical adquire centralidade entre as preocupações internacionais com a preservação do patrimônio da humanidade: haja vista sua fragilidade, inscreve-se na categoria do patrimônio imaterial.

\footnotetext{
${ }^{4}$ http://www.ictmusic.org/group/music-archaeology; http://ictm-music-archaeology-2015.blogspot.de/.
} 


\section{Revista de Arqueologia Pública}

Nesta perspectiva, foi contemplado dentro de um edital da Comunidade Europeia o projeto temático EMAP - European Music Archaeology Project, sedeado em Tarquínia e coordenado por Emiliano Li Castro, da Università di Viterbo. Iniciado em 2006, o projeto envolve 10 instituições europeias, com participação da Itália, Reino Unido, Suécia, Alemanha, Espanha e Áustria, e cooperação de instituições da Eslovênia, Finlândia e Irlanda. O projeto propõe-se ao mesmo tempo entender os sons do passado e reconstruir instrumentos musicais. Importante exemplo são os estudos dedicados à reconstituição do órgão grego, baseados principalmente nos vestígios do antigo órgão da cidade romana Aquincum (atual Budapeste), encontrado entre os escombros de um sindicato ou clube social de bombeiros, ironicamente destruído por um incêndio que, mais ironicamente ainda, possibilitou a preservação de importantes restos deste complexo instrumento, testemunho da engenharia mecânica da Antiguidade, que certamente servia ao divertimento e confraternização destes trabalhadores.

No encontro entre o patrimônio cultural e a memória social, os estudos realizados na interface entre Música \& História, em parceria com antropólogos e musicólogos, ganham outra dimensão, posto que tradições musicais vivas envolvem portadores de conhecimentos tradicionais, de natureza frágil, que demandam o registro, para não cair no esquecimento irreversível. Mas, mais que isto, o patrimônio vivo acarreta dimensões econômicas e sociais muito importantes, posto que na maior parte das vezes tem como representantes grupos excluídos do protagonismo econômico e social contemporâneo, e que, nas tradições musicais, têm arraigada sua identidade e seus laços de memória com as gerações passadas.

Alguns pesquisadores têm se apercebido do grande potencial que possuem as canções populares, urbanas ou rurais, no sentido de serem portadoras de memória social do grupo. Mais do que pelas letras das canções, a análise musical técnica revela aspectos formais, no ritmo, harmonia e melodia, que estão impregnados de heranças culturais étnicas formadoras dos grupos portadores destas canções, que tendem a desaparecer. É neste contexto que consideramos de grande valor o registro musical e etnográfico das canções entoadas até algumas décadas atrás por descendentes de imigrantes italianos da Serra do Rio Grande do Sul, como acompanhamento de atividades de produção e socialização do vinho. Exemplo disso encontramos no CD "Vino e Allegria", do Coro Monte Carlo, de Flores da Cunha. ${ }^{5}$ Estudos de iconografia musical mostram que este costume já estava presente

${ }^{5}$ CD "Vino e Allegria", Coro Monte Carlo, maestro Alcides Verza, coord. José Mascarello, ÂNIMA Produções, Farroupilha, 2011. 


\section{Revista de Arqueologia Pública}

na Grécia antiga, no século VI, como comprova um vaso ático do Pintor de Amásis (Fig. 04), e perdurou em várias regiões ao longo do Império romano, até o século VI, como mostram os mosaicos agrários das estações do ano, da França ao Líbano, Jordânia e Israel. Ou seja, a memória musical destes imigrantes italianos gaúchos, em uma escala de longa duração, conforme a tipologia de memória denominada por Jan Assmann como "memória cultural", que é labiríntica, ecoa e preserva uma tradição do mundo do trabalho rural que remonta à Antiguidade. A impregnação da música no mundo do trabalho está evidenciada desde períodos muito recuados na Grécia antiga, como nos mostra a terracota beócia com mulheres produzindo pão ao som da flauta (Fig. 05).

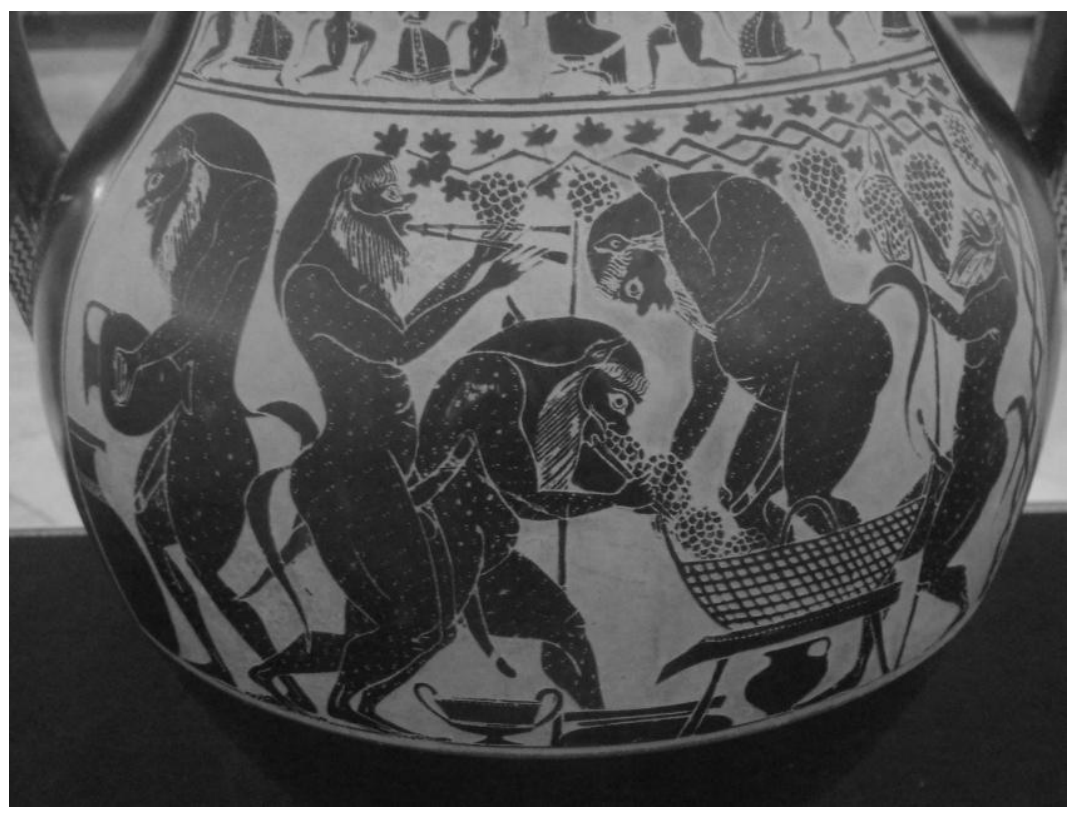

Figura 04 - Em cena retratando diferentes momentos da produção do vinho, sátiro toca aulos durante o pisoteio das uvas. Ânfora ática de figuras negras. Atribuída ao Pintor de Amasis. Ca. 540-530 a.C. Würzburg, Martin von Wagner Museum, L 265 e L 282. Foto: F. Vergara Cerqueira (2014). 


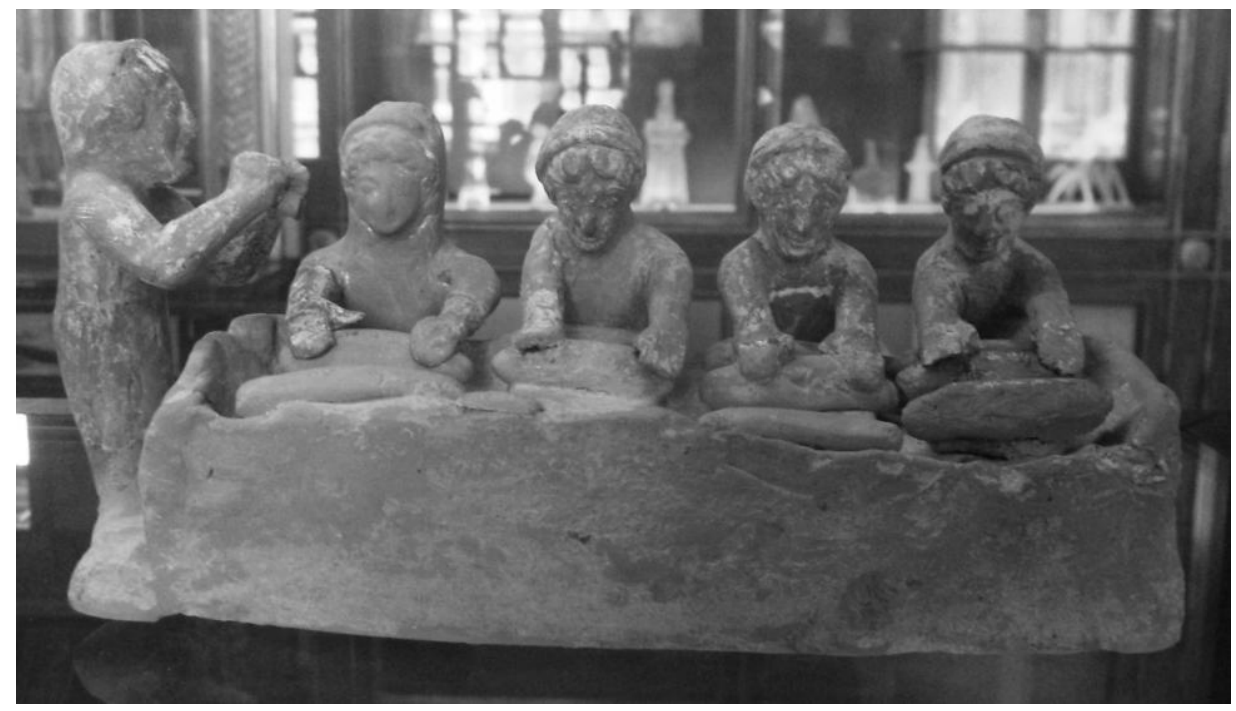

Figura 05 - Mulheres produzindo pão acompanhadas por auletes. Terracota beócia. Séc. VI a.C. Paris, Louvre, CA 804. Foto: F. Vergara Cerqueira (2014).

Vê-se que as memórias étnicas têm grande potencialidade de se impregnarem em manifestações musicais dos descendentes de grupos de imigrantes. O musicólogo Danilo Kuhn da Silva, interessado pela cultura de imigração pomerana no município de São Lourenço do Sul (RS), por esta singular ramificação étnica da imigração germânica, identifica, em algumas canções - que foram registradas em seu inventariado de tradições locais realizado durante o projeto Canto Coral nas Escolas - a memória de acontecimentos que envolveram os pomeranos, ainda na Europa, na época em que foram motivados a emigrarem. É sobre isto que lemos em seu artigo "A música pomerana como narrativa da memória cultural", publicada nos Cadernos do LEPAARQ (UFPel) ${ }^{6}$. O autor constata que estas canções funcionam como uma forma de relato e atualização da memória coletiva, como observa ao analisar as canções "A festa" e o "Casamento da Vovó", cujas letras foram por ele transcritas, trabalho ainda mais importante, tendo em vista que os pomeranos pertenciam a uma cultura ágrafa e que sua cultura e língua, portanto, não possuem registro escrito próprio (SILVA, 2014).

\section{Iconologia musical e cultura material}

Como abordas o estudo da música nas imagens e para a compreensão dos objetos?

Tenho particular interesse em explorar as potencialidades de estudo do passado musical a partir do cruzamento entre a cultura material e a iconografia. 


\section{Revista de Arqueologia Pública}

Tenho me dedicado ao longo de mais de uma década ao estudo da iconografia musical dos gregos antigos, o que me propiciou gerar uma interpretação, a partir da música, entendida como "fato social total", de aspectos muito variados da Grécia antiga, como guerra, religião, gênero, mulher, homoerotismo, esporte, política, educação, trabalho, dentre outros. A impregnação da cultura musical por fenômenos da memória social e das tradições tem me interessado bastante.

Cultura material e a música se encontraram, quando organizei uma exposição sobre a "camisola do dia", principal peça do enxoval das noivas brasileiras até a década de 1960, usada na sua primeira noite com seu esposo, preferencialmente branca, como símbolo da pureza inerente virgindade que se cobrava das mulheres de então. Para estudar o valor patrimonial destas peças da intimidade feminina, que vez por outra se encontram conservadas no fundo de armários, como herança da mãe ou avó, precisamos recorrer aos testemunhos orais, que trouxeram muito da significação desta peça, que nos ajudou a entender e muito a sociedade da época. Mas pensei que a música oportunizaria uma perspectiva mais profunda para a compreensão desta intimidade que transbordava neste exemplar da cultura material matrimonial brasileira e cristã de boa parte do século XX.

Pois o lamento amoroso do samba foi capaz de figurar a atmosfera mágica que o imaginário da camisola do dia carregava ${ }^{7}$. Estávamos em 1957, quando Herivelto Martins e Davi Nasser ${ }^{8}$ trouxeram a público a canção $A$ Camisola do Dia, interpretada por sua ex-esposa e parceira musical, Dalva de Oliveira, e consagrada mais adiante pela voz de Nélson Gonçalves, cujos versos reproduzimos parcialmente abaixo:

Amor, eu me lembro ainda

Era linda, muito linda

Um céu azul de organdi

\section{A camisola do dia}

Tão transparente e macia

Que eu dei de presente a ti

(...)

E eu era o dono de tudo

${ }^{7}$ http://www.scielo.br/scielo.php?pid=S0103-21862011000200004\&script=sci arttext

8 Herivelto de Oliveira Martins, carioca nascido em 1912 e falecido em 1992, foi compositor e cantor, tendo mantido relacionamento com a cantora Dalva de Oliveira (1936-1950), compôs várias músicas em parceria com David Nasser (1907-1980), jornalista e compositor mineiro, filho de imigrantes libaneses. 


\section{Revista de Arqueologia Pública}

\section{Do divino conteúdo}

Que a camisola ocultava ${ }^{9}$

$(\ldots)$

O "divino conteúdo", predicado que Ihe atribuem os versos de Herivelto Martins, pode ser interpretado como uma metáfora do sagrado, uma vez que a cor suave da camisola remete à pureza da noiva que se pressupunha virgem, onde estão implicados valores religiosos e sociais de forte adesão na sociedade da época. Creio que este caso exemplifica o profícuo caminho de interpretação da memória através do entrecruzamento entre cultura material e música. Exemplifica também como a música serve não somente para entender a própria música, mas a sociedade, partindo do pressuposto que funciona como um "fato social total".

${ }^{9}$ Grifos do autor. 